\title{
Embedding problem solving and use of data with routine supply chain procedures: District leadership and team-based approaches improve product availability in Rwanda
}

\author{
Alexis Heaton ${ }^{1 *}$, Amanda Ombeva ${ }^{1}$, Deogratias Leopold ${ }^{1}$, Golbert Kazoza ${ }^{1}$, Patrick Nganji1, Cathy Mugeni², \\ Megan Noel ${ }^{1}$, Yasmin Chandani ${ }^{1}$ \\ From The 2nd People that Deliver (2nd PtD) Global Conference on Human Resources in Supply Chain \\ Management \\ Copenhagen, Denmark. 29-30 October 2014
}

\section{Background}

In Rwanda, 30,000 volunteer community health workers (CHWs) treat children under five for pneumonia, diarrhoea and malaria. A 2010 community supply chain (SC) assessment identified a lack of SC skills and poor coordination between $\mathrm{CHWs}$, health centres $(\mathrm{HCs})$ and districts as barriers to $\mathrm{CHW}$ product availability. SC4CCM tested standard resupply procedures (RSPs) and multi-level quality improvement teams (QITs) to strengthen coordination and problem-solving between levels to improve supply chain processes and outcomes.

\section{Method}

In 2013, SC4CCM conducted a mixed-methods midline evaluation and an endline study in 2014 to understand sustainability and scalability of the QIT approach. A quantitative survey measured key supply chain indicators to compare results 12 months after launching the intervention (at midline), and another 12 months later to understand if results were sustained. Qualitative data at endline assessed enabling factors and barriers for scale up after the $\mathrm{MOH}$ began implementing RSPs and QITs nationally.

\section{Results}

Midline results showed that the team-based approach led to improved outcomes. CHWs in QIT districts had 25\% greater availability of the five community health products

\footnotetext{
* Correspondence: infosc4ccm@jsi.com

${ }^{1}$ JSI Research \& Training Institute, Inc. Washington DC, USA

Full list of author information is available at the end of the article
}

on the day of visit than the comparison group. Qualitative results confirmed the importance of multi-level teams and a structured approach in achieving results. Endline findings confirmed the role of district leadership in maintaining and scaling this intervention. While CHWs in all districts affirmed the value of the approach, establishment of QITs in new districts and continued use of data relied on leadership of $\mathrm{HC}$ staff, frequently predicated upon district staff engagement and participation.

\section{Discussion}

Product availability and performance of SC tasks among CHWs can be improved by establishing multi-level teams that aid coordination and communication across levels in the health system and use data to prioritize areas for problem solving and develop local solutions. To establish and maintain meetings, leadership and on-going engagement from district staff ensures HC staff call meetings and prioritize the activities among their many other tasks. Meetings should have a known agenda, be short, and have a consistent approach to the use of data for performance monitoring and identification of problems and solutions within the team's ability to address.

\section{Lessons learned}

CHWs are often isolated from the mainstream health system. Strengthening their connections with $\mathrm{HC}$ and district staff through teams improves coordination and sets a culture of continuous improvement. Engagement by district coaches is necessary to establish QITs and 
ensure HCs provide the necessary leadership to sustain meetings and the approach.

\section{Authors' details}

${ }^{1}$ JSI Research \& Training Institute, Inc. Washington DC, USA. ${ }^{2}$ Rwanda

Ministry of Health, Community Health Desk, Kigali, Rwanda.

Published: 17 December 2014

doi:10.1186/2052-3211-7-S1-P11

Cite this article as: Heaton et al:: Embedding problem solving and use of data with routine supply chain procedures: District leadership and team-based approaches improve product availability in Rwanda. Journal of Pharmaceutical Policy and Practice 2014 7(Suppl 1):P11.

Submit your next manuscript to BioMed Central and take full advantage of:

- Convenient online submission

- Thorough peer review

- No space constraints or color figure charges

- Immediate publication on acceptance

- Inclusion in PubMed, CAS, Scopus and Google Scholar

- Research which is freely available for redistribution

Submit your manuscript at www.biomedcentral.com/submit
C Biomed Central 